\title{
IMAGEN 1-2014: Calcinosis Cutis en Dermatomiositis del Adulto
}
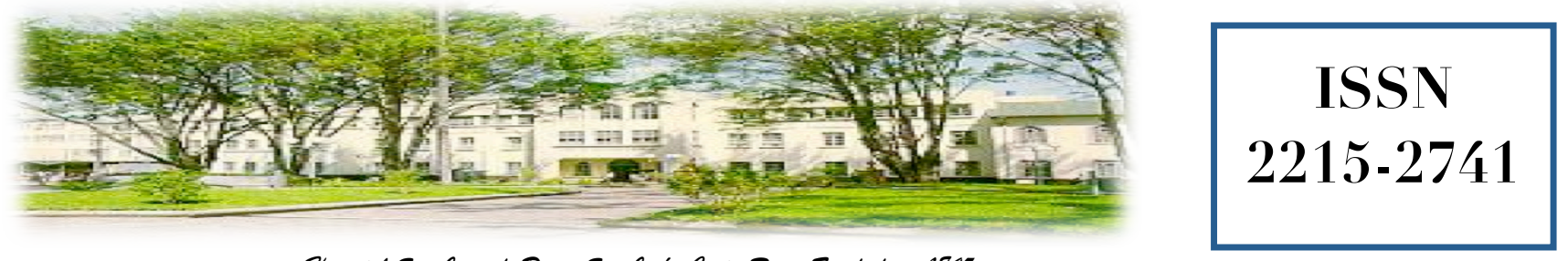

Haspital San quan de Dias, San Gosé. Casta Riua. Fundada en 1845

Recibido:

$16 / 01 / 2013$

Aceptado:

$20 / 02 / 2014$

Pablo Coste Murillo ${ }^{1}$ Eduardo Bonilla Trejos ${ }^{2}$

${ }^{1}$ Médico Residente de Medicina Interna. Sistema de Estudios de Posgrado UCR-CENDEISSS. Hospital San Juan de Dios. Correo electrónico: costepablo@gmail.com

${ }^{2}$ Médico Asistente Especialista en Reumatología. Sección de Medicina. Hospital San Juan de Dios.

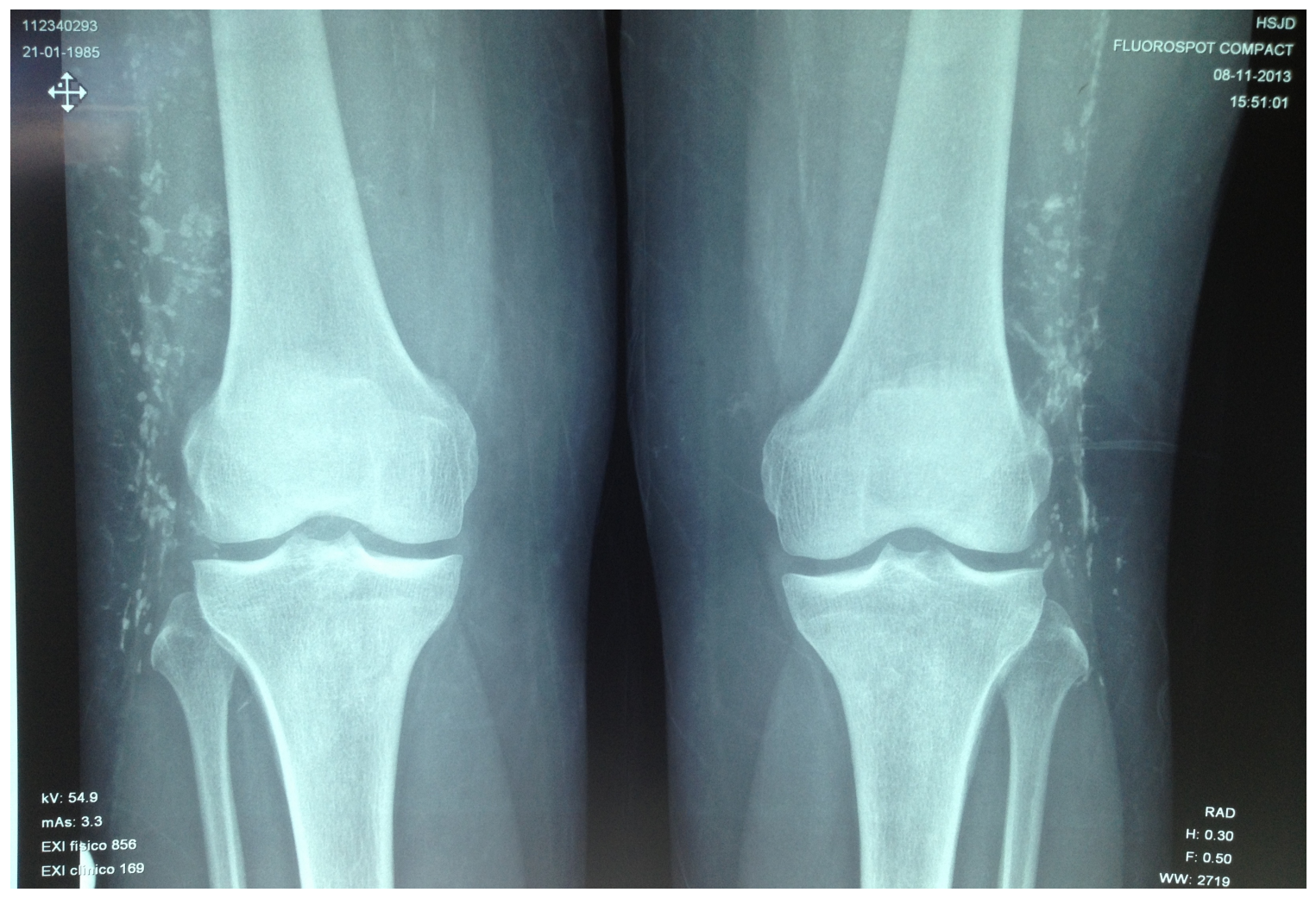




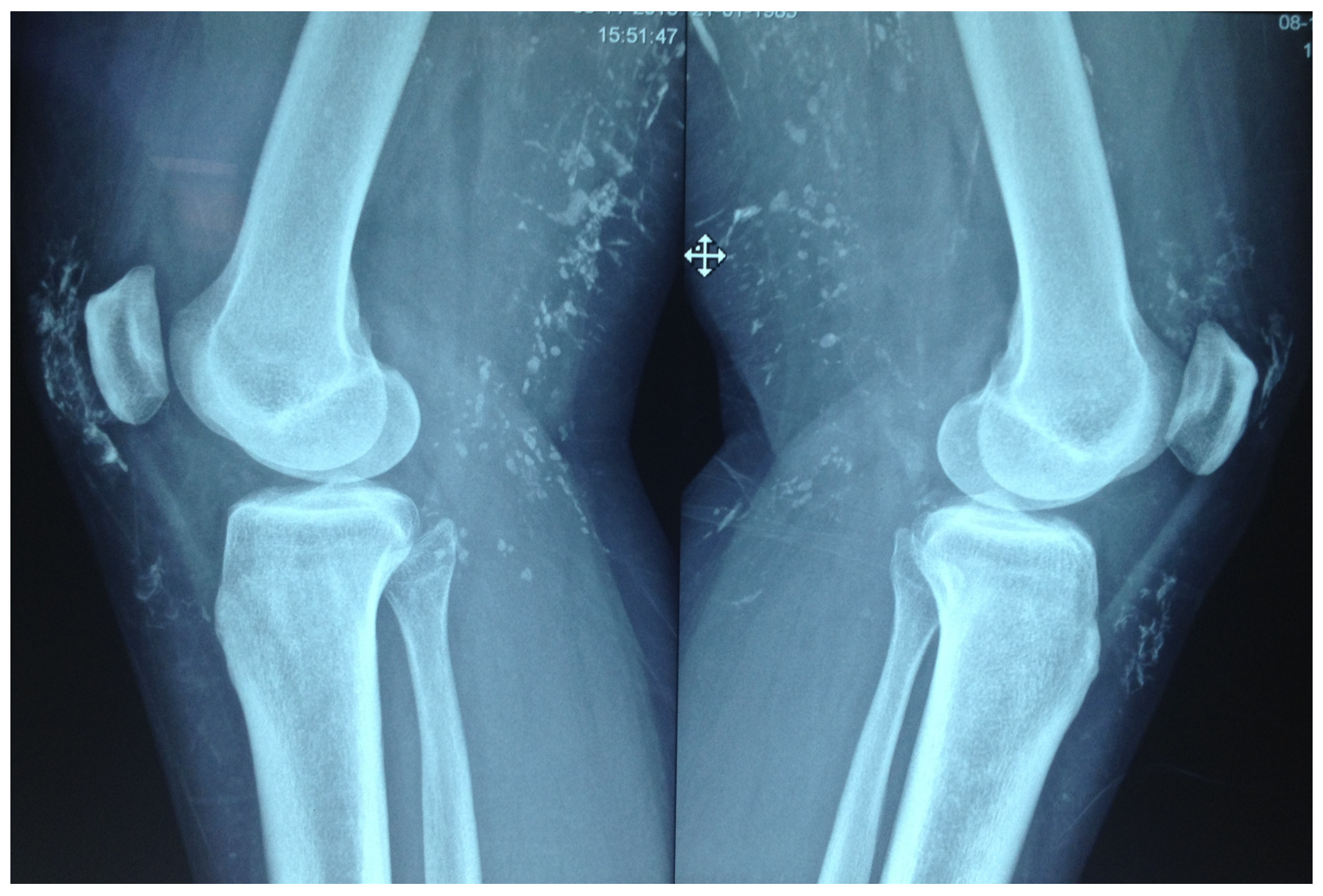

\section{RESUMEN DEL CASO.}

Femenina de 28 años, con diagnóstico de dermatomiositis desde 4 años previo a la consulta, en tratamiento con prednisona, azatioprina y plaquinol, con adecuada evolución.

Ingresó por gonalgia derecha y ataque al estado general. Por ultrasonido (US) se evidenció una bursitis prepatelar y la radiografía $(\mathrm{Rx})$ bilateral de rodillas no mostró alteraciones articulares, pero sí imágenes radiopacas compatibles con depósitos de calcio en tejidos blandos. Los niveles de calcio, fósforo, vitamina D y PTH estuvieron dentro de límites normales.

Los estudios por neoplasia asociada con su dermatomiositis fueron negativos. Completó tratamiento antibiótico por 14 días con excelente evolución clínica, con US control sin alteraciones y con $\mathrm{Rx}$ de rodillas control que mostró persistencia de las lesiones descritas.

\section{DISCUSIÓN}

La calcinosis cutis es una entidad nosológica que incluye depósitos insolubles de calcio en la piel y tejidos subcutáneos ${ }^{(1)}$. Estas lesiones pueden limitar los movimientos articulares, infectarse $u$ originar incapacidad importante ${ }^{(2)}$. Su fisiopatología no es del todo clara, pero aparentemente está implicado el daño al colágeno y a la matriz extracelular de fibrillas elásticas, alteraciones en los inhibidores de calcificación y niveles mitocondriales anormales de calcio y fósforo ${ }^{(3,4)}$.

Existen 4 subtipos de calcinosis: distrófica, metastásica, iatrogénica e idiopática, de los cuales la distrófica es la más comúnmente asociada a enfermedades reumatológicas ${ }^{(5,6)}$.

Es una manifestación que ocurre hasta en un 44$70 \%$ de los casos de dermatomiositis juvenil ${ }^{(7)}$, sin embargo, es poco frecuente en la dermatomiositis del adulto ${ }^{(8)}$. 
Se presenta el caso de una paciente con calcinosis cutis asociada a dermatomiositis del adulto.

\section{BIBLIOGRAFÍA}

1. Gutiérrez AWetter D. Calcinosis cutis in autoimmune connective tissue diseases. Dermatologic Therapy 2012;25:195-206.

2. $\mathrm{Wu}$ J Metz BJ. Calcinosis cutis of juvenile dermatomyositis treated with incision and drainage. Dermatol Surg 2008;34(4):575577.

3. Pugashetti R Shinkai K Ruben BS Grossman ME Maldonado J Fox LP. Calcium may preferentially deposit in areas of elastic tissue damage. J Am Acad Dermatol 2011;64(2): 296-301.

4. Walsh JS Fairley JA. Calcifying disorders of the skin. J Am Acad Dermatol 1995;33:693706.

5. Touart DM Sau P. Cutaneous deposition diseases: part II. J Am Acad Dermatol. 1998;39(4):527-546.

6. Balin S Wetter D Andersen L Davis M. Calcinosis Cutis Occurring in Association With Autoimmune Connective Tissue Disease. Arch Dermatology 2012;148(4):455-462.

7. Shah R Ellis S. Subcutaneous fat calcinosis in adult-onset dermatomyositis. BMJ Case Reports 2011. 